OPEN ACCESS

Edited by:

Su Shiung Lam,

University of Malaysia

Terengganu, Malaysia

Reviewed by:

Rock Keey Liew,

Universiti Malaysia

Terengganu, Malaysia

Huan Pang

Yangzhou University, China

*Correspondence:

Heting Zhou

contrist@163.com

Specialty section:

This article was submitted to Electrochemical Energy Conversion and Storage,

a section of the journal

Frontiers in Energy Research

Received: 13 December 2019

Accepted: 14 April 2020

Published: 12 June 2020

Citation:

Zhou H and He J (2020) Synthesis of the New High Entropy Alloy and Its Application in Energy Conversion and Storage. Front. Energy Res. 8:73. doi: 10.3389/fenrg.2020.00073

\section{Synthesis of the New High Entropy Alloy and Its Application in Energy Conversion and Storage}

\author{
Heting Zhou ${ }^{1 *}$ and Jiangwei He ${ }^{2}$ \\ ${ }^{1}$ Department of Civil Engineering and Architecture, Zhejiang Industry Polytechnic College, Shaoxing, China, ${ }^{2}$ Department of \\ Research and Development, Zhejiang Runtu CO. LTD., Shaoxing, China
}

In order to explore the methods of energy saving and promoting energy regeneration, this paper presents the synthesis and application of new high energy alloy materials in energy conversion and storage. A new type of high entropy alloy material was prepared by analyzing its high strength, tempering resistance and softening resistance. The electrochemical properties of the new type of high entropy alloy were studied according to its microstructure and as cast structure. The experimental results show that compared with fesn2, the new high entropy alloy material has greater advantages in capacity, electrochemical performance, capacity stability and magnification in the process of cyclic charging, at low annealing temperature, the solid Co nanoparticles are further transformed into hollow $\mathrm{CO}_{3} \mathrm{O}_{4}$ nanospheres by the kirkentel effect on the nanoscale. $\mathrm{NC}-\mathrm{CO}_{3} \mathrm{O}_{4}$ nanocomposites as zinc air battery cathodes exhibit excellent OER and ORR properties: low overpotential $352 \mathrm{mv}$, high initial reduction potential $0.91 \mathrm{v}$ and half wave potential $0.87 \mathrm{v}$, high open circuit voltage $1.44 \mathrm{v}$, capacitance $387.2 \mathrm{mah} / \mathrm{g}$, and excellent cycle stability. Nico bimetallic phosphide nanotubes derived from the high entropy alloy-74 are efficient electrocatalysts for water decomposition.

Keywords: high entropy alloy, materials, energy conversion, storage, electrochemical performance, fuel cell FeSn 2

\section{INTRODUCTION}

With the rapid growth of population and economy, the huge global energy consumption has led to the unsustainable development of fossil fuels, resulting in serious environmental problems due to the excessive development and use of fossil fuels. With the dual crisis of energy and environment, it is more and more urgent to develop renewable energy to reduce, recycle and even replace the use of fossil fuels (Yurchenko et al., 2016). One of the key technologies of renewable energy revolution is effective energy conversion and energy storage. Energy conversion and storage efficiency depend on electrochemical reactions (Yi et al., 2017), as the most typical examples are hydrogen production by water splitting, power generation by redox reaction of fuel cells, catalytic reduction of $\mathrm{CO}_{2}$, and ion recycling of batteries and supercapacitors for energy storage. Electrode materials largely determine the efficiency of an electrochemical energy storage and conversion device (Michael et al., 2017). Effective surface area, optimized pore size distribution and crystallinity are the most important factors affecting electrode materials. Therefore, considering the practical application, it is very important to develop new electrode materials with high performance (Wang et al., 2016).

The development of material science has always been accompanied by the development of human civilization, in which metal materials play a decisive role in human history and civilization. 
So far, more than 30 kinds of practical alloy systems have been applied to all aspects of human life, for example, steel materials for the pillar of the national economy, aluminum alloy next to steel, magnesium alloy with the lightest weight among practical metals, etc. (Wang et al., 2016; Mike et al., 2017). In the 1970's, the development and application of binary intermetallic compounds such as $\mathrm{Ti} \mathrm{Al}$ and amorphous alloys (metallic glass) have not broken away from the traditional design concept of alloy materials, that is, they are all based on one (content generally more than $50 \%$ ) or two metal elements, on the basis of which other elements are purposefully added to improve the metal performance (Jia and Yang, 2016). Nowadays, with the development of aviation, aerospace, electronics, communication and other technologies as well as machinery, chemical industry, energy and other industries, more and more requirements are put forward for the performance of materials. However, the traditional concept of synthesis has been unable to support today's strong demand. Traditional single materials can no longer meet the use requirements, so human beings have stepped into a new era of synthetic materials, in which metal materials have developed from the original pure metal to synthetic metal (Chao et al., 2016). Many achievements have been made in the research of synthetic metals. In 1995, Taiwan scholar Ye Junwei creatively put forward a new concept of alloy design of the high entry alloy, which completely broke the traditional concept of alloy design. The idea has laid a foundation for the development of synthetic metals, but the theory has not been put into practice. In the past 20 years, many scholars and teams have participated in the research of the high entry alloy and accumulated a lot of research results. The most typical one is high entropy alloy. The original high entropy alloy has been proved to be unsuitable for reversible lithium battery storage, but the subsequent work solved this problem and made the high entropy alloy as an effective energy storage material (Zhi et al., 2017). In addition to direct use, the high entropy alloy is also used as a support material to cover active nano materials for energy conversion reaction or as a precursor material to obtain a variety of other high entropy alloy materials through different processing methods (Wu et al., 2016). For example, Aijaz et al. used ZIF8 as carbon and nitrogen source for template, furfuryl alcohol and $\mathrm{NH}_{4} \mathrm{OH}$ to prepare the high entropy alloy porous carbon material for $\mathrm{CO}_{2}$ adsorption and oxygen reduction reaction (ORR). Wang et al. Mixed ZIF-8 nanoparticles with polyacrylonitrile (PAN) solution, prepared ZIF-8 / PAN fiber by electrospinning, and then calcined at $500^{\circ} \mathrm{C}$ under nitrogen protection to obtain the high entropy alloy porous carbon material. It is reviewed the research results of the high energy alloy in recent years, including its organizational structure and performance, as well as its application in super capacitors and fuel cells. As a new type of sustainable energy conversion and storage technology, it has excellent efficiency, high energy density and environmental friendliness. However, the research on the synthesis of high entropy alloy is not thorough, and there are many defects in its performance analysis.

Based on the above problems, this paper presents the synthesis of new high entropy alloy and its application in energy conversion and energy storage. The properties of high entropy alloy are analyzed and the capacity of charging and discharging is compared. The specific research route is as follows:

(1) The properties of high entropy alloy are analyzed, including wear resistance, hardness, corrosion resistance, tempering resistance and softening resistance.

(2) The preparation methods of new high entropy alloy materials are introduced, and the advantages and disadvantages are analyzed.

(3) The microstructure of the new high entropy alloy was simplified.

(4) The application research of new high entropy alloy material includes the electrochemical absorption and release properties of new high entropy alloy material and its application in practice.

(5) Conclusion and focus of future research.

\section{MATERIALS AND METHODS}

\section{The High Entropy Alloy Performance} High Wear Resistance of the High Entropy Alloy

As we known, the wear resistance of materials is related to their hardness. The harder the materials are, the higher the wear resistance (Ye et al., 2016; Xu et al., 2018). So it is not difficult to find that the high entropy alloy also has high wear resistance. The change of alloy elements has a great influence on the wear resistance of the high entrance alloy. Through the study of the adhesion wear behavior of $\mathrm{Al}_{\mathrm{x}} \mathrm{CoC}_{\mathrm{x}} \mathrm{CuFeNi}$, it is found that with the increase of $\mathrm{Al}$ content, the number of BCC phase increases. BCC phase can improve the hardness and reduce the wear coefficient of the alloy, while the wear changes to oxidation wear (Su et al., 2016). In the process of oxidation wear, oxide film will be formed on the surface, which will help to improve the wear resistance of the alloy. The research shows that the wear resistance of the alloy is significantly improved by replacing $\mathrm{Cu}$ element in $\mathrm{AlCoCrFeCuNi}$ by Mo element. In addition, with the increase of Fe content, the wear resistance of the alloy

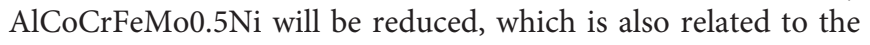
decrease of its hardness. It can be seen from the above that the wear resistance of the high entry alloy is the best by properly adjusting the type and content of elements (Stepanov et al., 2017).

High Strength and Hardness of the High Entropy Alloy The special organizational structure of the high entry alloy determines its unique performance. Similar to other solid solution metals, the high entrance alloy has a strong strengthening effect for solid solution. When the alloy solidifies and crystallizes, the solid solution atoms will block the movement of dislocations, so the solid phase strength and hardness are very high. There is no grain boundary in the amorphous phase of the alloy, which makes the slip movement more difficult, so the solid phase strength is higher. Similarly, the middle nano phase and the second phase of the high-intensity alloy can further enhance the solid phase strength. In addition, due to the difference of atomic size among the constituent elements, the lattice distortion will hinder the dislocation movement and increase the solid strength. The hardness characteristics of as-cast structure of the 
high entrance alloy in various systems are shown in Table 1, the hardness of the as-cast structure of the high entrance alloy is 600-900 hv, which is no less than that of carbon steel and alloy carbon steel after complete quenching and hardening. The hardness of the alloy can be further adjusted by changing the content of alloying elements (Sheng et al., 2018).

\section{Excellent Corrosion Resistance of the High Entropy Alloy}

The high entropy alloy has a simple phase structure, may also contain amorphous, nanocrystalline and low free enthalpy, which determines its strong corrosion resistance (Zhang et al., 2018a). For the high-corrosion-resistant alloy containing $\mathrm{Ti}, \mathrm{Cr}, \mathrm{Ni}$, and $\mathrm{Cu}$, the corrosion resistance of the corrosion-resistant elements can be fully exerted, which can ensure that the high-corrosionresistant alloy will not be corroded in strong acid environment. Oxide film can not only improve wear resistance but also corrosion resistance. The existence of some elements in the alloy is conducive to the formation of oxide film, but also to improve corrosion resistance. Nano and amorphous phases in the alloy can also effectively improve the corrosion resistance between dendrites (Shi et al., 2016). If there is segregation in the fiber structure of the alloy, it may aggravate the corrosion tendency of the alloy. The corrosion resistance of the high entrance alloy as cast structure of various systems is shown in Table $\mathbf{1}$.

\section{Excellent Tempering and Softening Resistance of the High Entropy Alloy}

The high-temperature tempering can not only change its structure and atomic size, but also precipitate more nano particles and amorphous phases, which makes the high-temperature alloy still have high or even higher hardness. Therefore, the high entrance alloy does not soften after tempering, but has higher hardness (Rizzardi et al., 2018). For example, the above alloy is annealed at high temperature of $1,000^{\circ} \mathrm{C}$, holding time is $12 \mathrm{~h}$, and then cooled to room temperature in furnace. The hardness of the alloy is basically unchanged, sometimes even precipitation hardening occurs. In contrast, carbon steel and high-temperature and high-speed steel (only up to $550^{\circ} \mathrm{C}$ ) cannot do this, but also perform better than other non-ferrous alloys. In addition, the soft magnetic properties and high resistivity are also significant characteristics of the high entrance alloy. The high entropy alloy containing $\mathrm{Al}$ and $\mathrm{CR}$ also has excellent oxidation resistance up to $1,100^{\circ} \mathrm{C}$. The high entrance alloy has excellent properties, compared to traditional alloy.

\section{Preparation Method of the New High Entropy Alloy Material}

The first method to prepare the new high entrance alloy material is vacuum arc furnace casting, which is also the most traditional and applied method. Subsequently, the multi-element highfunction alloy coating was successfully prepared by magnetron sputtering, for example, a new type of high entropy alloy material, alfeticrzncu, was successfully prepared by mechanical alloying. Li Xiaobing et al. tried to prepare the new high entrance alloy material coating by thermal spraying. Yao Chenzhong et al. successfully prepared the amorphous the new high entrance alloy materialfe 13.8 co $28.7 \mathrm{ni} 4.0 \mathrm{mn} 22.1$ bi $14.9 \mathrm{tm} 16.5$ film by potentiostatic electrochemical deposition. The new high-speed alloy material can be made of block material, coating material and film material by melting casting, forging, powder metallurgy, spraying method and coating method. With the increase and improvement of the preparation process of the new high-speed alloy material, its application field will be expanded greatly.

\section{Preparation of High Entropy Alloy Powder}

The preparation method of high entropy alloy powder is mainly mechanical alloying, which is easy to obtain nanocrystalline or amorphous particles with uniform structure and component distribution. Varalaksh of Madras Institute of technology in India prepared cunicoznalti, alfeti crzncu system high entropy alloy by this method, and studied its structure and properties. Weiting et al. prepared alfecrconi high entropy alloy by this method. Figure 1 shows the classification of preparation methods for different forms of samples.

\section{Preparation of High Entropy Alloy Matrix Composite}

The preparation of metal high entropy alloy can be divided into the above five categories, and the common preparation methods of high entropy alloy matrix composite materials are mainly self propagating high temperature synthesis (SHS). Li Bangsheng's research group is devoted to the research of high entropy alloy matrix composite materials, and Wang Yanping, his doctoral student in the literature, uses the "SHS + melting casting" method to prepare alcrfecon $\mathrm{ICu}-10 \% \mathrm{TiC}, \mathrm{CrFeCoNiCuTi}$ $10 \% \mathrm{TiC}$ high entropy alloy matrix composites.

TABLE 1 | List of hardness and corrosion resistance of high entropy alloy ( $\times$ indicates no corrosion).

\begin{tabular}{|c|c|c|c|c|c|c|c|c|}
\hline \multicolumn{2}{|c|}{ High entropy alloys } & \multirow{2}{*}{$\begin{array}{c}\text { CuTivFe } \\
\text { NiZrCo } \\
620\end{array}$} & \multirow{2}{*}{$\begin{array}{c}\text { CuTiVFe } \\
\text { NiZrCo+3\%B } \\
660\end{array}$} & \multirow{2}{*}{$\begin{array}{c}\text { AlTiVFe } \\
\text { NiZrCo } \\
780\end{array}$} & \multirow{2}{*}{$\begin{array}{c}\text { AlTiVFe } \\
\text { NiZrCo+3\%B } \\
770\end{array}$} & \multirow{2}{*}{$\begin{array}{c}\text { MoTiVFe } \\
\text { NiZrCo } \\
780\end{array}$} & \multirow{2}{*}{$\begin{array}{c}\text { AlTiVFe } \\
\text { NiZrCoCr } \\
770\end{array}$} & \multirow{2}{*}{$\begin{array}{c}\text { Mo TiVFeNi } \\
\text { ZrCoCrPd } \\
820\end{array}$} \\
\hline Hardness & As-cast & & & & & & & \\
\hline & $\begin{array}{l}\text { Annealing at } 1,000^{\circ} \mathrm{C} \text { for } \\
12 \mathrm{~h} \text {, furnace cooling }\end{array}$ & 610 & 680 & 790 & 780 & 780 & 880 & 810 \\
\hline \multirow[t]{3}{*}{ Corrosion resistance } & $\mathrm{HCL}(1 \mathrm{~mol} / \mathrm{L})$ & $x$ & $x$ & $\times$ & $x$ & $\times$ & $\times$ & $x$ \\
\hline & $\mathrm{H}_{2} \mathrm{SO}_{4}(1 \mathrm{~mol} / \mathrm{L})$ & $x$ & $\times$ & $\times$ & $\times$ & $\times$ & $\times$ & $x$ \\
\hline & $\mathrm{HNO}_{3}(1 \mathrm{~mol} / \mathrm{L})$ & $x$ & $x$ & $x$ & $\times$ & $x$ & $\times$ & $x$ \\
\hline
\end{tabular}




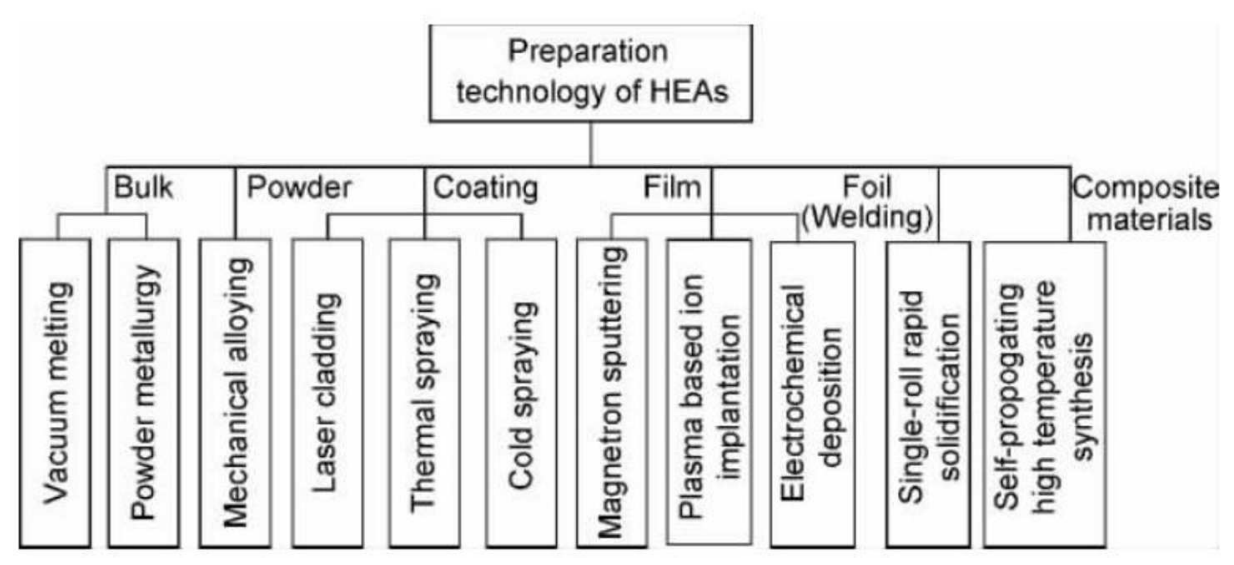

FIGURE 1 | Research and preparation methods of different forms of samples.

\section{Microstructure Characteristics of the New High Entropy Alloy Material \\ Simplified Microphase Structure}

According to the classical Gibbs phase ratio, the number of equilibrium phases in the alloy system of various elements, and the number of phases formed during non-equilibrium solidification. According to the characteristics of traditional alloys, it is believed that many kinds of main element alloys will produce many kinds of intermetallic compounds, which will deteriorate the mechanical properties of alloys. However, it is found that the new high-density alloy material microstructure has a simple BCC or FCC phase or amorphous state, which is not inclined to form brittle intermetallic compounds, and the number of phases obtained is far less than, which phenomenon can be well-explained according to Gibbs free energy equation

$$
\Delta G_{m i x}=\Delta H_{m i x}-T \Delta S_{m i x}
$$

In the formula, the mixing entropy and the mixing enthalpy $\left(\Delta H_{m i x}\right)$ are in a competitive position, and the mixing entropy plays a leading role in the high temperature stage. Therefore, the large mixing entropy of the new high-temperature alloy material will expand the dissolution range of the end-to-end solid solution to a certain extent, thus forming a simple multicomponent miscible phase, which is particularly obvious in the hightemperature stage (Zhang et al., 2018b).

\section{Nanocrystallization and Amorphization}

Under the action of high mixed entropy, some components of the new high entropy alloy material will precipitate nanophase structures or even amorphous structures in the as-cast state (Liu et al., 2017). The main reason for the tendency of alloy nanocrystallization is related to the kinetic theory, because when the new high entropy alloy material melts, the contained elements are disorderly arranged into a disordered liquid. After solidification, due to the diffusion and redistribution of multiple elements, the Nucleation and growth delay are conducive to

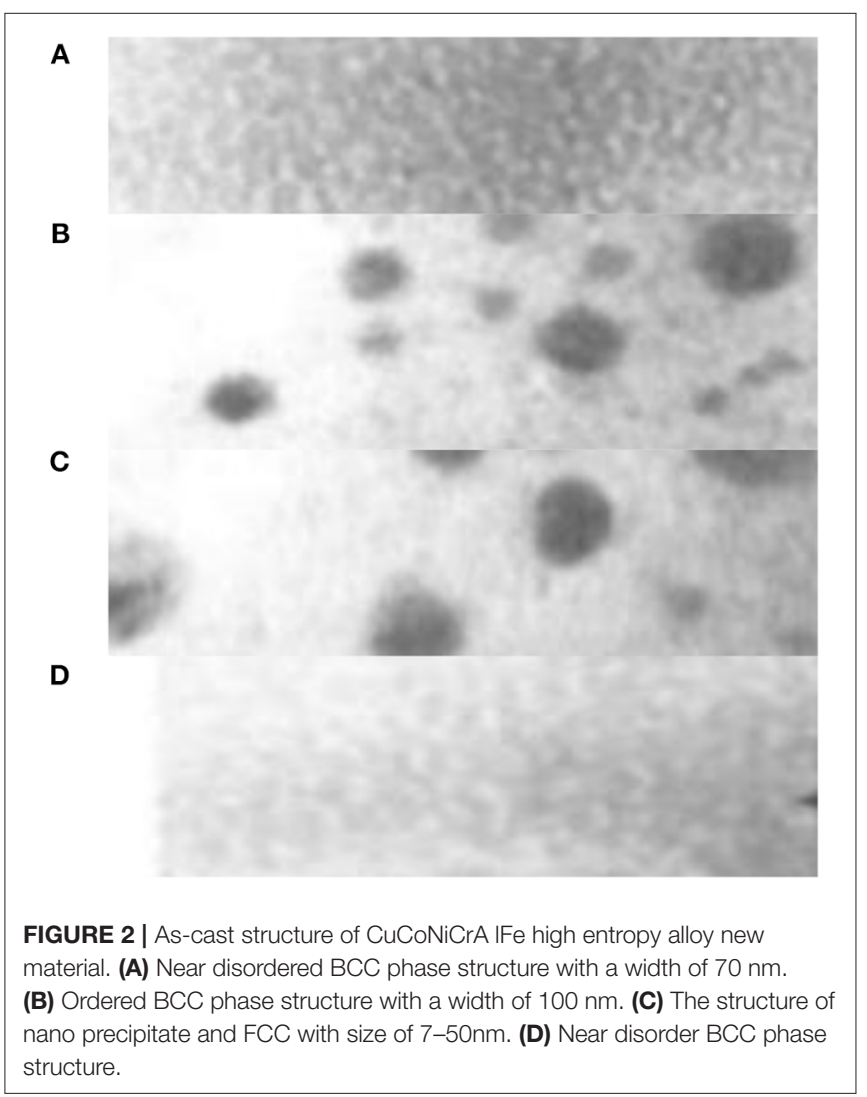

the formation of nanophases (Gao et al., 2016). For rapid solidification or vacuum coating, the lattice distortion of the new high entropy alloy material can show the tendency of nanocrystallization and even amorphization due to the difference in atom size. Figure 2 is the as-cast structure of $\mathrm{CuCoNiCrA}$ lFethe high entropy alloy material, where the width of the a region is about $70 \mathrm{~nm}$, which belongs to the nearly disordered BCC phase structure; the width of the $b$ region is about $100 \mathrm{~nm}$, which belongs to the ordered $\mathrm{BCC}$ phase structure; the $\mathrm{c}$ region 
is a nano precipitate The size is about $7-50 \mathrm{~nm}$, which is close to the FCC phase structure; the d region is a nano-precipitate, about $3 \mathrm{~nm}$, which also belongs to the nearly disordered BCC phase structure.

\section{APPLICATION RESEARCH OF THE NEW HIGH ENTROPY ALLOY MATERIAL}

The electrochemical performance of the new high energy alloy material and its application in super capacitor and fuel cell were studied, and its application in energy conversion and storage was verified.

\section{Electrochemical Absorption and Release Performance of the New High Entropy Alloy Material}

In Figures 3,4, it is shown that the first three charge and discharge conditions of the new high entropy alloy material and $\mathrm{FeSn}_{2}$ material at a current density of $50 \mathrm{mAg}^{-1}$.

It can be seen from the analysis of Figure 3 and Figure 3 that under different capacities and voltages, the new high entropy alloy reflects different situations through three times of charging and discharging. In the case of the first charge and discharge, when the voltage is 0.3 , the discharge capacity is about 760 $\mathrm{mAh} / \mathrm{g}-1$, when the voltage is 1.2 , the charge capacity is about 310 $\mathrm{mAh} / \mathrm{g}-1$, and its capacity starts to be higher than the discharge. In the case of the second charge and discharge, when the voltage is 1.2, the capacity of charging and non-charging is the same, and then the capacity of charging is higher than that of non-charging mode; in the case of the third charge and discharge, the situation is the same as that in figure (a) and figure (b).In addition, the formation of surface oxides will also lead to the formation of $\mathrm{Li}_{2} \mathrm{O}$ and irreversible capacity. After the first cycle, the second charge discharge is almost the same as the third charge discharge, indicating the reversible charge discharge reaction. Compared with $\mathrm{FeSn}_{2}$ material, the new high entry alloy material shows obvious high capacity.

Figure 5 shows the comparison of the cycle stability and rate performance between the new high entrance alloy material and $\mathrm{FeSn}_{2}$ material.

Figure 5A compares the cyclic performance of the new high entrance alloy material and $\mathrm{FeSn}_{2}$ material at a current density of $150 \mathrm{mAhg}^{-1}$. Obviously, compared with FeSn 2 , the new high entry alloy material shows improved cycle stability. After 25 cycles, the new high entrance alloy material maintains a charging capacity of $500 \mathrm{mAhg}^{-1}$, while the $\mathrm{FeSn}_{2}$ material sample only has a capacity of $150 \mathrm{mAhg}^{-1}$ after the same number of cycles.

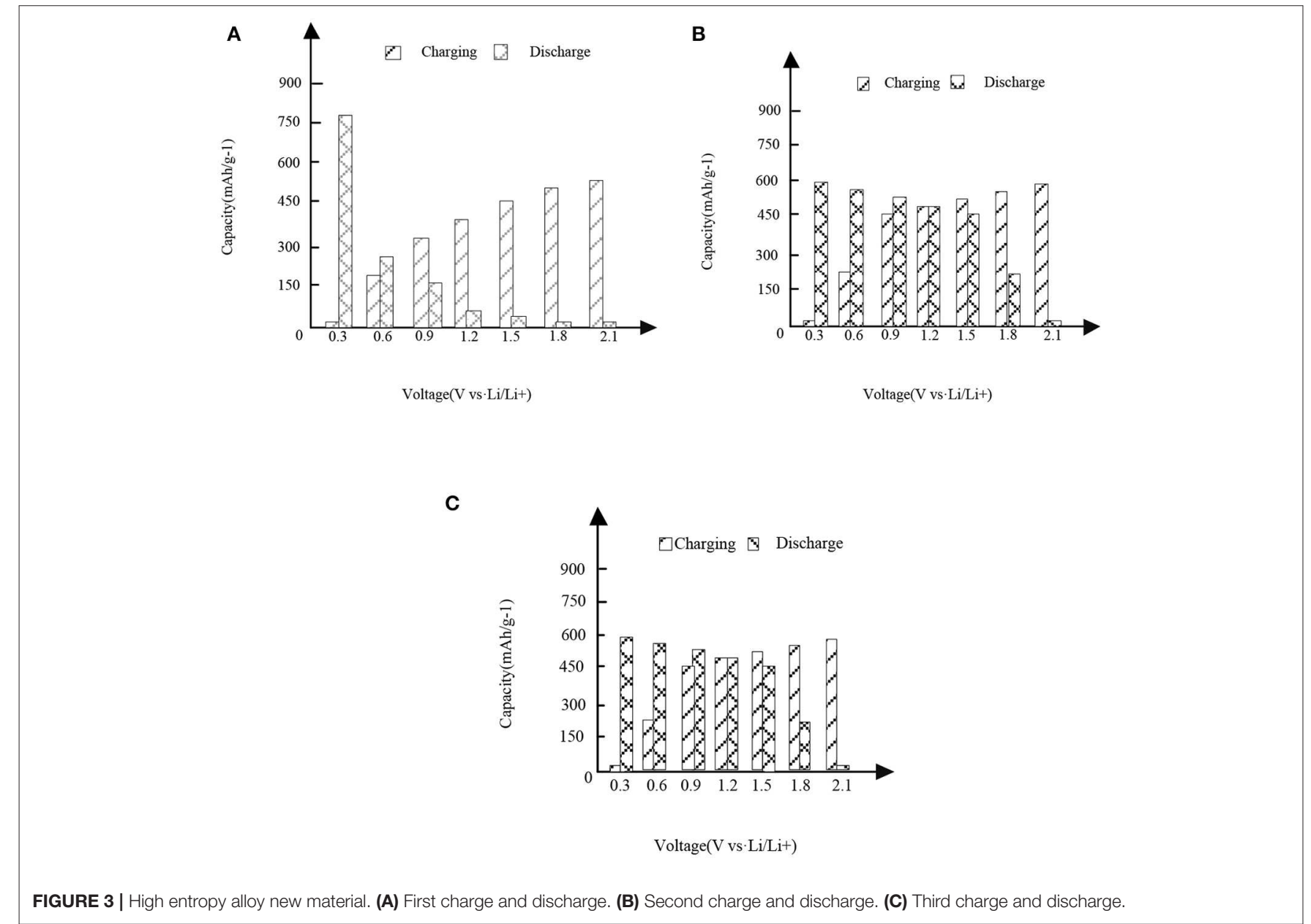




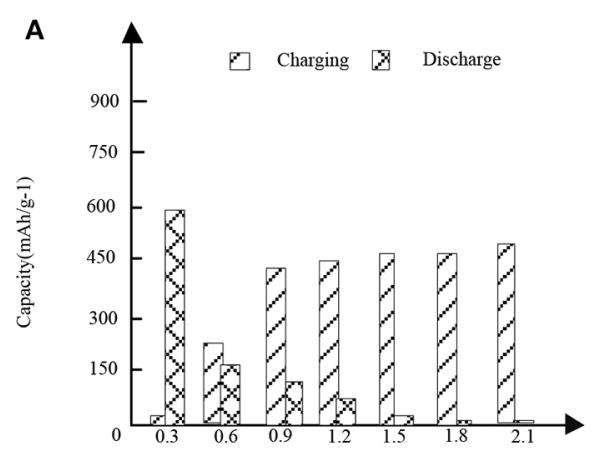

Voltage( $(\mathrm{V}$ vs $\cdot \mathrm{Li} / \mathrm{Li}+)$

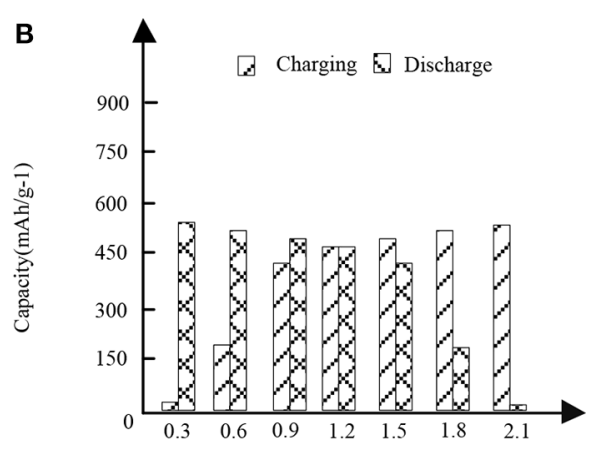

Voltage $(\mathrm{V}$ vs $\cdot \mathrm{Li} / \mathrm{Li}+)$

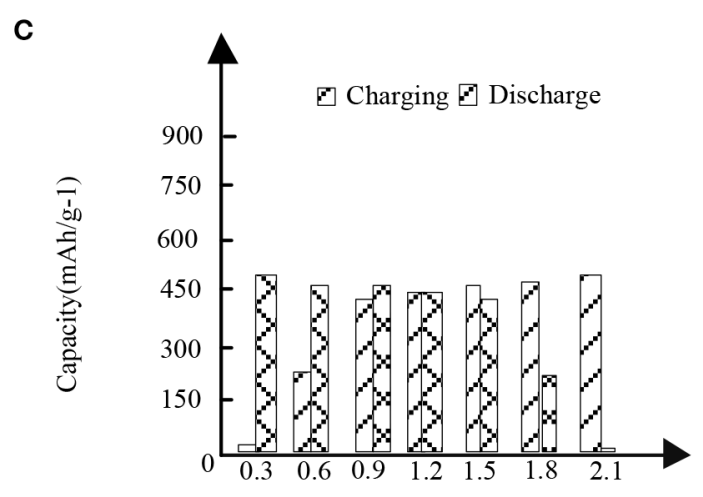

Voltage(V vs $\cdot \mathrm{Li} / \mathrm{Li}+)$

FIGURE 4 | The first three charges and discharges of the new high entropy alloy material and FeSn2 material at the current density of 50 mAg ${ }^{-1}$. (A) First charge and discharge. (B) Second charge and discharge. (C) Third charge and discharge.

The enhanced cycling performance is attributed to the slow down effect of the high entrance alloy on the volume change and the limitation of the agglomeration of $\operatorname{cosn}_{2}$ nanocrystals. Figure 5B compares the magnification properties of the new high entropy alloy material and $\mathrm{FeSn}_{2}$ material. The electrodes were charged at different current densities and discharged at a current density of $50 \mathrm{mAg}^{-1}$. Obviously, the new high entrance alloy material shows better rate performance than $\mathrm{FeSn}_{2}$ material. It is considered that the improvement of the rate performance is mainly due to the following factors: firstly, the high entropy alloy can act as the conductive network of the material nanocrystals; secondly, the nanocrystals with small size and good dispersion are conducive to the rapid transport of lithium ions; thirdly, the materials located between the high entropy alloy in layers are conducive to the wetting of the electrolyte. Therefore, the high entrance alloy sheet is more conducive to the internal ion transport between the electrolyte interfaces.

Figure 6 shows the Nyquist of the new high entrance alloy material and $\mathrm{FeSn}_{2}$ after 5 and 25 cycles. For the new high entrance alloy material, RSEI remained almost unchanged after 5 and 25 cycles, indicating that the structure of SEI membrane remained stable after the first cycle. The stability of SEI film can prevent the active materials from being exposed in the electrolyte and prevent the further decomposition of the electrolyte, which is conducive to the stability and reversible cycle of the new high entropy alloy material. However, after increasing the number of cycles for $\mathrm{FeSn}_{2}$ materials, $\mathrm{R}_{\mathrm{f}}$ and $\mathrm{R}_{\mathrm{ct}}$ increased significantly. In addition, the $\mathrm{R}_{\mathrm{e}}$ of $\mathrm{FeSn}_{2}$ material samples has increased significantly, which is speculated to be caused by the shedding of active materials. In contrast, the change in Re of the new high entropy alloy material is small, which indicates that the presence of the high entropy alloy suppresses the volume expansion during charge and discharge, thereby reducing the shedding of the active material. The relatively small changes in $R_{f}$ and $R_{c t}$ of the new high entropy alloy material indicate that the introduction of the high entropy alloy buffers, limits, and disperses FeSn 2 materials to better maintain electrode integrity during cycling. It is also explains why the new high entropy alloy material has better cycle stability and rate performance.

\section{Application of the New High Entropy Alloy Material in Super Capacitor}

Supercapacitor or electric double-layer capacitor (EDLC) is a kind of electrochemical device with huge capacitance and high capacity, which are widely used in devices requiring fast 


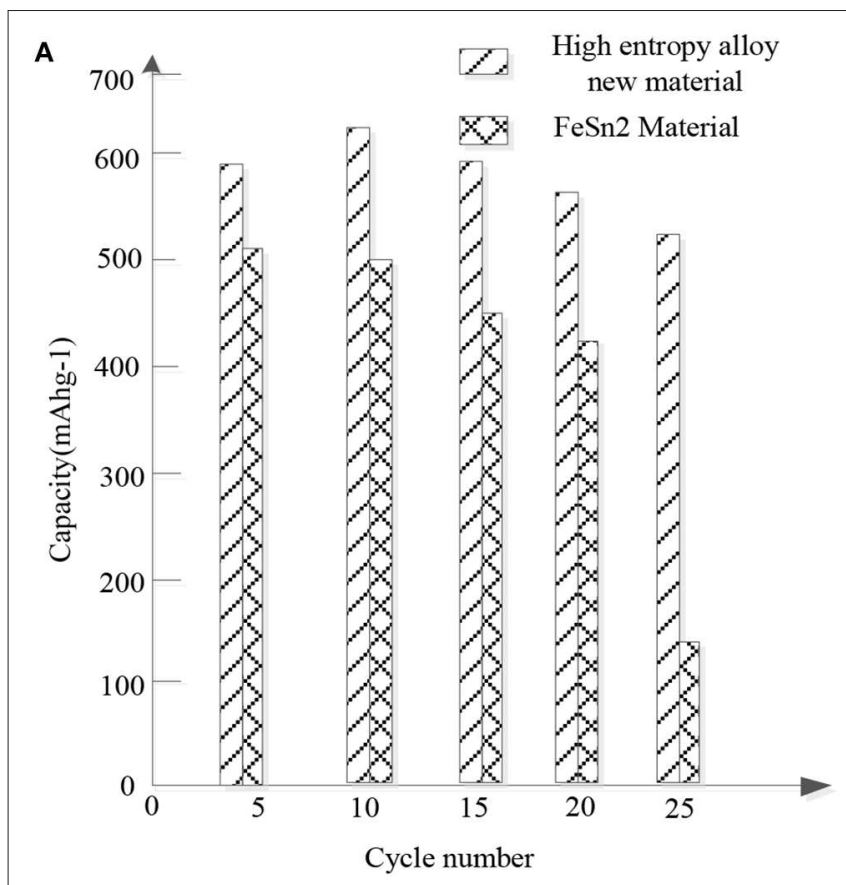

B

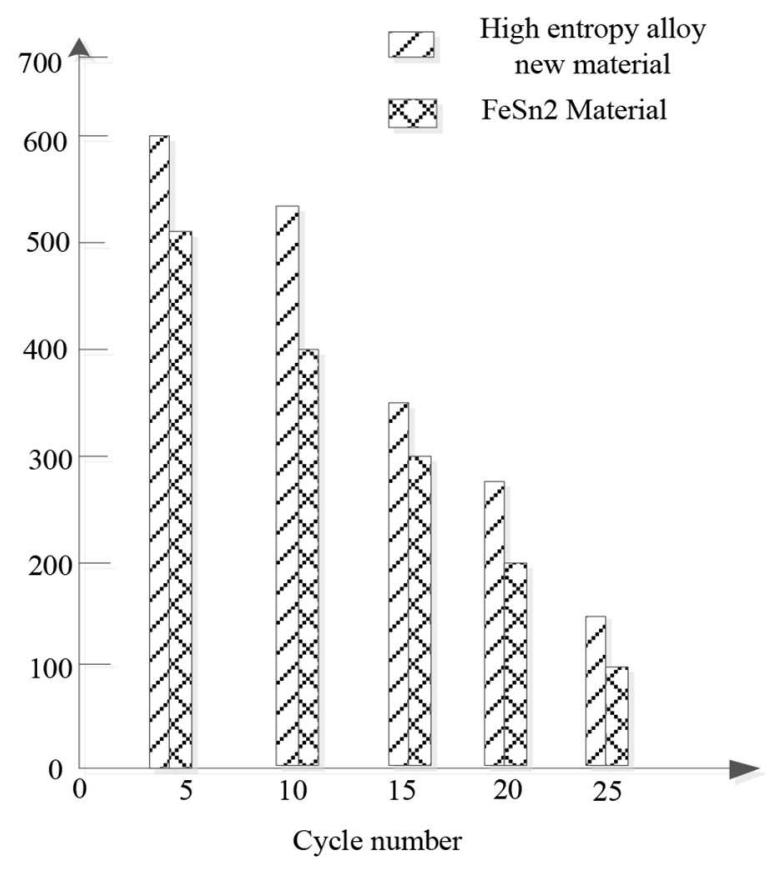

FIGURE 5 | Comparison of cyclic stability and multiplicative properties between the new high entropy alloy material and $\mathrm{FeSn}_{2}$ material samples. (A) Cyclic stability. (B) Ratio of performance.

charge/discharge cycles. Supercapacitors do not use conventional solid-state media of ordinary capacitors. These devices can store electric energy in the electrochemical double layer (EDL) formed by electrolyte ions on the electrode surface, or the electrochemical redox reaction in the surface area of electrode materials. The key point of super capacitor is to improve energy density. In order

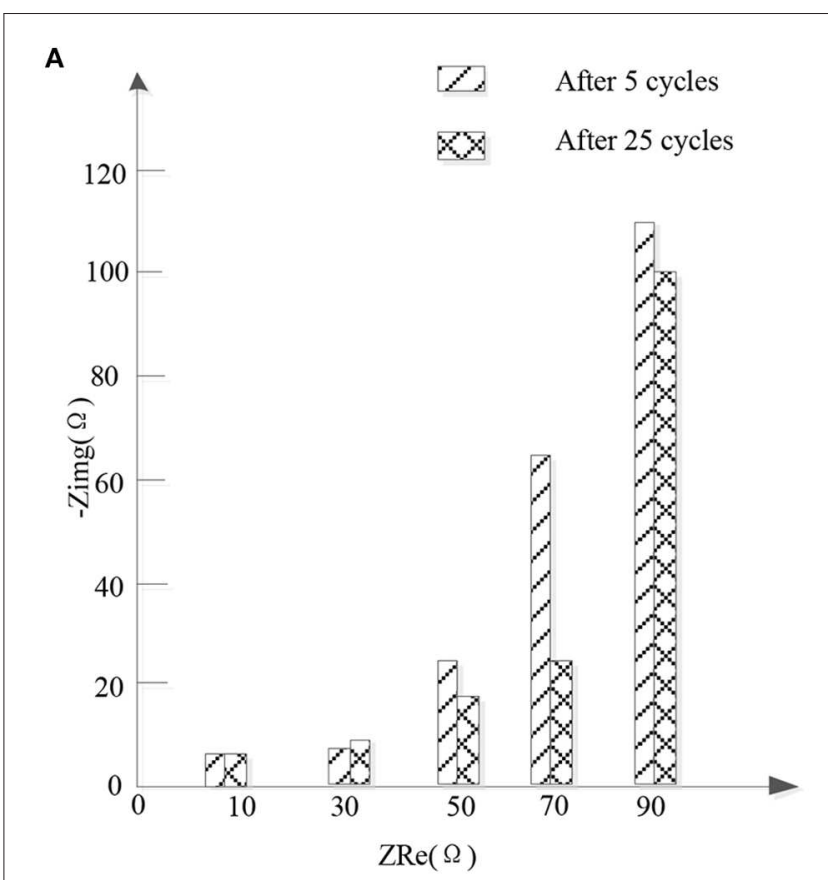

B

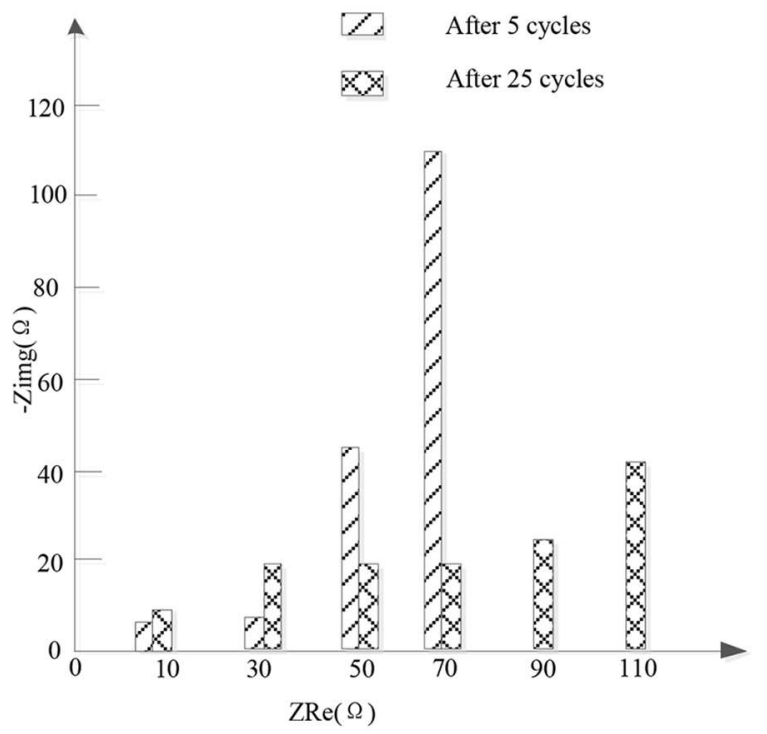

FIGURE 6 | Nyquist conditions of new high entropy alloy and $\mathrm{FeSn}_{2}$ material samples after 5 and 25 cycles. (A) High entropy alloy new material. (B) FeSn material.

to further improve the capacity, new electrode materials need to have good conductivity, high surface area and adjustable pore size. Because of the compliance with these standards, the new high entry alloy material has become a potential material for manufacturing super capacitors.

The new high entrance alloy material can also be used as an effective active material and a composite substrate for supercapacitors. In order to further study the practical 


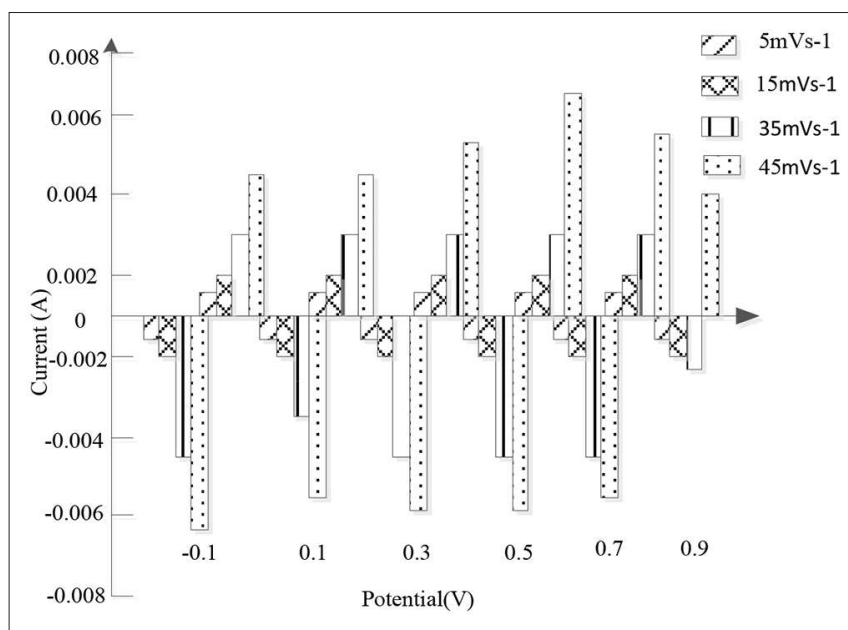

FIGURE 7 | The current state diagram of nitrogen-deposited porous carbon at a potential of $-0.1-0.9 \mathrm{v}$ in $1 \mathrm{M}$ sulfuric acid.

application performance of the material, especially the flexible energy storage performance, the material was used in the flexible solid-state hybrid battery (SSHC) equipment. It is found that the maximum volume energy density of SSHC is $5.1 \mathrm{~mW}$ $\mathrm{h} / \mathrm{cm}^{3}(210 \mathrm{~W} \mathrm{~h} / \mathrm{kg})$, which is much higher than other materials reported at present.

As a typical 2D single-layer inorganic carbon material, the high-density alloy is widely used as electrode material. The new high-density alloy material can greatly improve its rate performance and cycle stability. The hybrid electrode structure assembled by the high-density alloy nano sheet and inorganic nano materials has the following advantages: (1) it can effectively improve the connectivity between the individual electroactive species, shorten the transmission path between the ion and the electrolyte; (2) the mixing of the two materials can retain the advantages between the two, play a synergistic role, and ultimately improve the electrochemical performance of the whole system. The active site rich NIS nanorods(R$\mathrm{NiS}$ ) and rGOcomposites (R-NiS/rGO) were prepared by in situ vulcanization with $\mathrm{Ni-MOF}-74 / \mathrm{rGO}$ as parent. The nanostructured NIS nanorods $(200 \times 800 \mathrm{~nm})$ prepared by the high-density alloy are uniformly wrapped on the $\mathrm{rGO}$, which provides an ideal electronic conductivity for the rapid energy storage. The layered porous structure of the nanocomposite promotes the rapid entry of liquid electrolyte into the active material. In addition, experiments and theoretical calculations show that the NIS nanorods in the mixed electrode exhibit active redox reactions. R-NiS/rGO composite shows high specific capacity, excellent ratio performance and good cycle stability. In $2 \mathrm{M} \mathrm{KOH}$ electrolyte, when the current of R-NiS/rGO mixed electrode increases from 1 to $50 \mathrm{~A} / \mathrm{g}$, the capacitance only decreases from 744 to $600 \mathrm{C} / \mathrm{g}$. After 20,000 cycles, the initial capacitance is still higher than $89 \%$, showing excellent stability.

Due to the advantages of simple preparation, low cost, high chemical stability and good conductivity, the nanofibers in the high-density alloy are also widely used as electrode materials for supercapacitors. A 3D crosslinked PANI / nitrogen deposited porous carbon fiber (3DCPPC) was prepared by in-situ polymerization of aniline with zif- 8 derived nitrogen deposited porous carbon fiber. Figure 7 shows the cyclic voltammetry of porous carbon deposited by nitrogen at a potential of $-0.2 \sim 0.8 \mathrm{~V}$ in $1 \mathrm{~m}$ sulfuric acid, indicating that the rapid ion diffusion and electron transfer are attributed to low internal resistance and ideal capacitive behavior. The constant current charge and discharge test with current intensity of $1 \mathrm{~A} / \mathrm{g}$ shows that 3D-CPC (755 F/g) has higher specific capacitance than 3D crosslinked PANI (504 F/g) and nitrogen deposited porous carbon (325 $\mathrm{F} / \mathrm{g}$ ). As the current intensity increases from 1 to $20 \mathrm{~A} / \mathrm{g}$, the specific capacitance of 3D-CPC only decreases from 755 to $618 \mathrm{~F} / \mathrm{g}$, indicating that the material has excellent transmission performance. In addition, $91.2 \%$ of the capacitance remains after 1,000 cycles at a high current intensity $(20 \mathrm{~A} / \mathrm{g})$, which proves that the $3 \mathrm{D}$-CPC material has good cycle stability. For supercapacitors, the excellent electrochemical properties of $3 \mathrm{D}$ CPC materials are mainly attributed to two aspects: first, nitrogen deposition porous carbon can provide more active sites for the rapid transfer of ions and electrons; second, the high structural stability of 3D cross-linked PANI fiber can prevent the expansion and contraction of electrode materials.

In order to obtain this hybrid array, CNTFswere first immersed in a mixed solution containing $\mathrm{Zn}^{2+}$ and $\mathrm{Co}^{2+}$, and the product was heated at $350{ }^{\circ} \mathrm{C}$ under the protection of inert gas to obtain $\mathrm{CNTFs}{ }^{@} \mathrm{Zn} \mathrm{Co}_{2} \mathrm{O}_{4}$ nanowire array (NA).

Subsequently, $\mathrm{Zn} \mathrm{Co}_{2} \mathrm{O}_{4}$ NA provides $\mathrm{Zn}^{2+}$ and $\mathrm{Co}^{2+}$ ions and acts as a framework to grow bimetallic Zn/Co-ZIF (CNTFs @ $\left.\mathrm{Zn} \mathrm{Co} 2 \mathrm{O}_{4}^{@} \mathrm{Zn} / \mathrm{Co}-\mathrm{ZIF}\right)$ in situ. NTFs @ $\mathrm{Zn} \mathrm{Co}_{2} \mathrm{O}_{4} @ \mathrm{Zn} / \mathrm{Co}-$ ZIF HA was heated in air at $350^{\circ} \mathrm{C}$ to convert it into CNTFs $@ \mathrm{Zn} \mathrm{Co} 2 \mathrm{O}_{4} @ \mathrm{Zn} \mathrm{Co} 2 \mathrm{O}_{4} \mathrm{ha}$, and then CNTFs @ $\mathrm{Zn} \mathrm{Co}_{2} \mathrm{O}_{4}$ @ $\mathrm{Zn}$ co-s HA was obtained by secondary reaction with thioacetamide at $70^{\circ} \mathrm{C}$. CNTFs @ $\mathrm{Zn} \mathrm{Co}_{2} \mathrm{O}_{4} @ \mathrm{Zn}-\mathrm{Co}-\mathrm{S}$ is used as cathode and CNTFs @ $\mathrm{H}-\mathrm{Co}_{3} \mathrm{O}_{4} @ \mathrm{CNC} \mathrm{HA}$ as anode to assemble FACS equipment. The specific capacitance of the device is $117.18 \mathrm{mF} / \mathrm{cm}^{2}$ at the current $10 \mathrm{~mA} / \mathrm{cm}^{2}$ and 67.5 $\mathrm{mF} / \mathrm{cm}^{2}$ as the current intensity is $10 \mathrm{~mA} / \mathrm{cm}^{2}$. A complete self charging power supply system includes a flexible fiber coaxially asymmetric supercapacitor (FACSS) and a flexible triboelectric Nanogenerator (FTENGs), which can collect and store energy for flexible electronic devices at the same time. The excellent electrochemical performance of the FACS device also shows in its high regional energy density, which is $32.01 \mu \mathrm{W} \cdot \mathrm{h} / \mathrm{cm}^{2}$ when the regional power density is $6,698.42 \mu \mathrm{W} / \mathrm{cm}^{2}$. In addition, when the power density increased to $7,000 \mu \mathrm{W} / \mathrm{cm}^{2}$, the energy density of the device remained at $12.38 \mu \mathrm{W} \mathrm{h} /$ $\mathrm{cm}^{2}$, indicating that $\mathrm{CNTFs}^{@} \mathrm{ZnCo}_{2} \mathrm{O}_{4}^{@} \mathrm{Zn}$-Co-S HA material had a strong synergistic effect. The excellent electrochemical performance of self-assembled FACS is mainly attributed to its unique layered and porous structure, which can provide more electronic active sites and smart ion diffusion path.

Based on the above analysis, it is found that the new high entropy alloy material shows excellent electrochemical properties in the application of super capacitor. The main advantages of the material are as follows: (1) high structural stability prevents the expansion and contraction of the electrode; (2) the pore structure 
provides a large number of electroactive sites and electrolyte transfer channels, and enhances the ion transport in the whole structure; (3) the highly crosslinked structure of the high-density alloy provides an efficient channel for electron transfer and ion diffusion in the charge discharge process. Although great progress has been made in this field, most of the researches are mainly on ZIF derived nanomaterials. In the future, it should develop a variety of other preparation and application of the high entropy alloy derived nanomaterials.

\section{Application of the New High Entropy Alloy Material in Fuel Cell}

In the past few years, fuel cell as a new type of sustainable energy conversion technology has been widely concerned because of its excellent efficiency, high energy density and environmental friendliness. The performance of fuel cell mainly depends on several important electrocatalytic reactions, including ORR, HER and OER. In general, the formation of $\mathrm{H}-\mathrm{H}$ and $\mathrm{O}=\mathrm{O}$ bonds in water is very slow or requires very high electrochemical potential. In order to overcome these limitations, it is necessary to use electrocatalyst to reduce the superpotential driving water oxidation and proton reduction. In recent years, the new high entropy alloy material based electrode material has been proved to be a promising electrocatalytic water cracking material.

In order to further enhance the electrocatalytic performance of the new high entropy alloy material based catalyst, various new chains and nodes are designed to optimize the catalytic activity of the new high entropy alloy material. These methods mainly include: (1) embedding $\pi$ - conjugated organic ligands into the framework to prolong the recombination time of electron hole; (2) combining molecular catalyst, semiconductor quantum dots, metal nanoparticles and metal ions with the new high entropy alloy material; (3) constructing ultra-thin 2D the high entropy alloy nanofilms. The last method has several advantages, including fast mass transfer, superior electron transfer and high percentage between the exposed catalytic active surface and the unsaturated metal site, which ensure high catalytic activity and unique surface atomic structure and bonding arrangement which are easy to identify and adjust. Through the preparation of 2D ultra-thin nicothe high entry alloy framework, its structure is shown in Figure 8. The performance of electrocatalytic OER with $\mathrm{GC}$ and $\mathrm{Cu}$ as working electrodes was studied. When GC is used as electrode, the corresponding over-voltage is $250 \mathrm{mV}$ when the current density is $110 \mathrm{~mA} / \mathrm{cm}^{2}$. When $\mathrm{Cu}$ is used as electrode, the over-voltage is only $189 \mathrm{mV}$ when the current density is $10 \mathrm{~mA} / \mathrm{cm}^{2}$. In addition, in $1 \mathrm{M} \mathrm{KOH}$ solution, the NiCothe high entry alloy framework showed incredible long-term stability (200 h), far higher than the commercial $\mathrm{RuO}_{2}$ electrocatalyst $(\sim 11 \mathrm{~h})$. The ultra-high OER electrocatalytic activity of the NiCothe high entropy alloy framework is mainly attributed to the synergistic effect between the unsaturated metal sites and the porous ultra-thin NiCothe high entropy alloy.

Under the appropriate temperature, the high entropy alloy can be directly converted into the new high entropy alloy material through carbonization. The preparation diagram of the new high entropy alloy material is shown in Figure 9. These metal nanoparticles can provide electrocatalytic sites, moreover, which can greatly improve the conductivity and stability of the whole new high entropy alloy material. For example, carbonco nanocomposites were obtained by carbonizing $\mathrm{Zn}$ and the new high entropy alloy material and used as dual functional electrocatalysts for ORR and OER. Zif-67 was grown on the surface of zif- 8 as a template to form a typical core-shell structure, which was then transformed into a double shell nano cage with Co- $\mathrm{N}$ deposited graphite carbon as the shell and $\mathrm{N}$ deposited porous carbon as the inner shell by carbonization and acid etching. Due to the large active surface area and high diffusion kinetics of the reactants, this novel structure exhibits unique catalytic activity and durability in terms of ORR and OER. First-principles theoretical calculations indicate that the high catalytic activity of both reactions is due to the strong and favorable adsorption of the rate-dependent intermediate product $\left(\mathrm{OOH}^{*}\right)$ on the Co lattice with non-coordinated hollow sites and high density $\mathrm{C}$ atoms. In addition, the active $\mathrm{C}$ sites in the para-position of the deposited graphite-type and pyridine-type nitrogen atoms also showed higher activity in the ORR and OER reactions, respectively.

The results show that metal oxides, metal phosphates and metal sulfides can be used to enhance the electro catalytic activity of the new high entrance alloy material. It is reported that a high efficient bifunctional oxygen catalyst was prepared by $\mathrm{Co}$ based the high entrance alloy, and the hollow $\mathrm{Co}_{3} \mathrm{O}_{4}$ nanospheres were coated on the carbon felt. Firstly, CO the high entropy alloy grows on the carbon felt, and then pyrolyses to form Co nanoparticles fixed on the carbon nano sheet. At low annealing temperature, the solid Co nanoparticles are further transformed into hollow $\mathrm{Co}_{3} \mathrm{O}_{4}$ nanospheres by the kirkentel effect on the nanoscale. $\mathrm{NC}-\mathrm{Co}_{3} \mathrm{O}_{4}$ nanocomposites as zinc air battery cathodes exhibit excellent OER and ORR properties: low overpotential $352 \mathrm{mv}$, high initial reduction potential $0.91 \mathrm{v}$ and half wave potential $0.87 \mathrm{v}$, high open circuit voltage $1.44 \mathrm{v}$, capacitance $387.2 \mathrm{mah} / \mathrm{g}$ and excellent cycle stability. Nico bimetallic phosphide nanotubes derived from the high entropy alloy-74 are efficient electrocatalysts for water decomposition. The over potential of HER and OER are 129 and $245 \mathrm{mV}$, respectively, when the current density is $10 \mathrm{~mA} / \mathrm{cm}^{2}$. They can also be used as cathode and anode catalysts for alkaline aqueous solution cracking. The voltage of the electrolyzer is $1.59 \mathrm{v}$ at the current density of $10 \mathrm{~mA} / \mathrm{cm}^{2}$. The hollow $\mathrm{CoS}_{2}$ nanotube array derived from CO the high-intensity alloy was used as an efficient dual-function electrocatalyst for all water cracking. Hollow $\mathrm{CoS}_{2}$ nanoarrays have hierarchical pores, large surface area and abundant surface active sites. Compared with $\mathrm{Co}_{3} \mathrm{O}_{4}$ electrode, $\mathrm{CoS}_{2}$ shows more excellent OER and HER electrocatalytic properties. When the current density of total water cracking in alkaline solution is $10 \mathrm{~mA} / \mathrm{cm}^{2}$, the battery voltage is $1.67 \mathrm{v}$, and the current of electrode can be stable for $20 \mathrm{~h}$ under bending state. The above research shows that the new high energy alloy material provides a new functional material for the development and efficient utilization of fuel cells. 


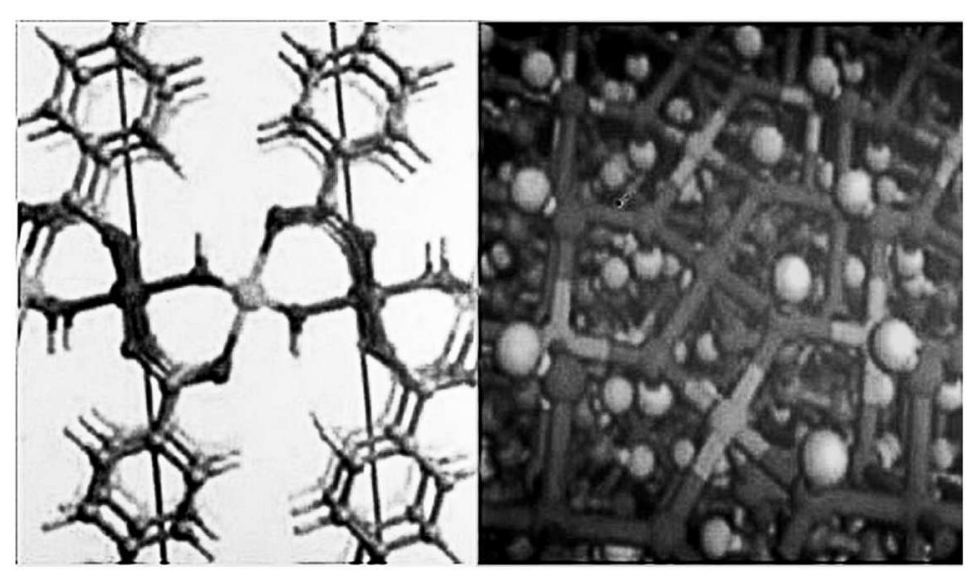

FIGURE 8 | Crystalline structure of NiCo high entropy alloy frame. Note: dark gray, C; Light gray, H; Red, O; Purple, Co; Green, Ni.

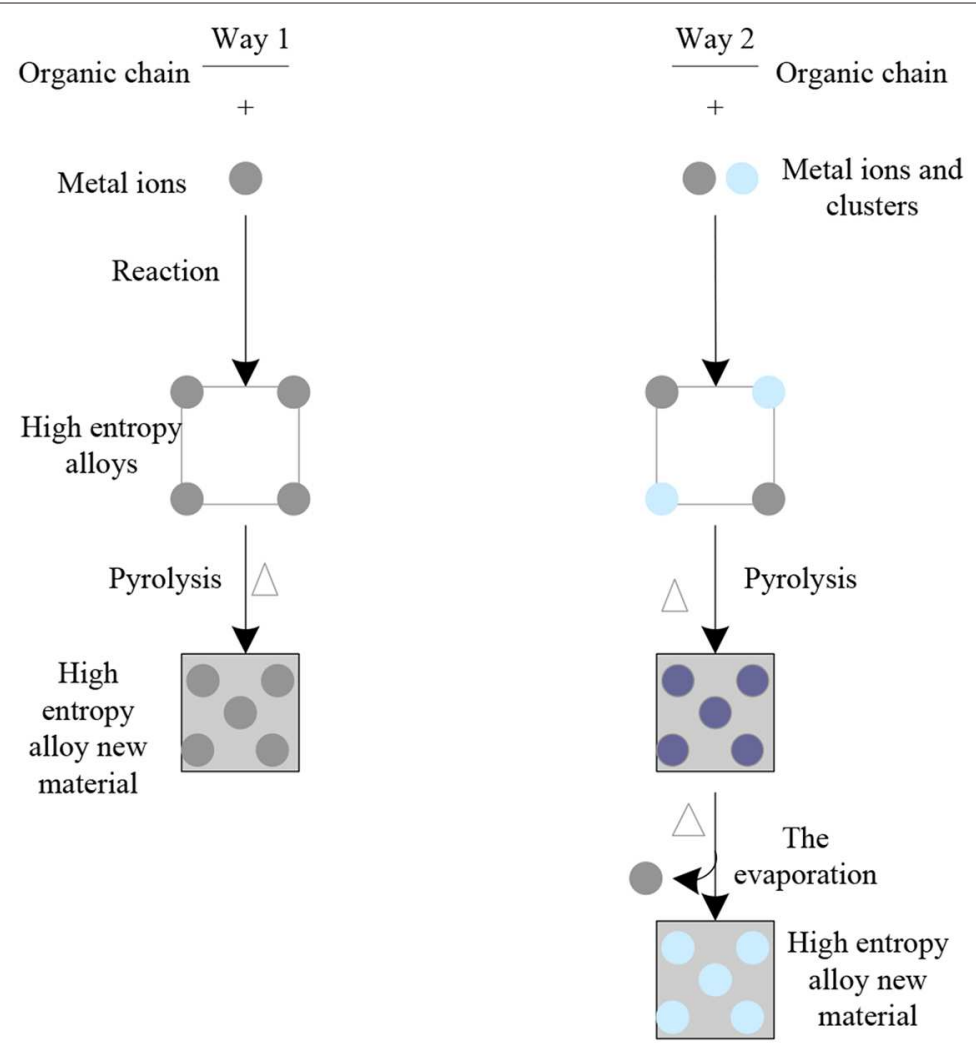

FIGURE 9 | Schematic diagram of preparation of new high entropy alloy materials.

\section{CONCLUSIONS AND PROSPECT}

Based on the urgent need for high-performance energy storage and conversion systems, the development of new electrode materials is crucial (Zhou et al., 2018). The new high entropy alloy material has the characteristics of large surface area, high porosity, adjustable pore size and controllable structure, which advantages can well meet the requirements of highperformance electrode materials. The successful preparation of the new high-performance alloy material and its application in the field of electrochemical energy storage and conversion is an exciting interdisciplinary research field. In this article it is summarized the application of the new high entropy alloy material in super capacitors and fuel cells (ORR, HER, and OER). As an electrode material, the new high entropy alloy material exhibits high capacitance, excellent rate performance, and good cycle stability. Although the new high entropy alloy material has carried out a lot of work in energy storage and conversion, it still faces many challenges, such as: 
(1) At present, the preparation cost of the new high entropy alloy material is relatively expensive. In practical application, it is necessary to reduce the preparation cost of the new high entropy alloy material;

(2) the precursor types of the new high entropy alloy material are few, and the obtained new high entropy alloy material is mainly metal oxides, sulfides, carbon materials and their composites, so it is still necessary to develop other new high entropy alloy materials;

(3) the surface area of electrode material is small, which leads to the limited contact area between electrode material and electrolyte;

(4) the high crystallinity of the new high entrance alloy material limits the diffusion distance of electrolyte in the material;

(5) most of the new high entry alloy materials have poor stability in aqueous solution, and there are problems of decomposition and frame collapse;

\section{DATA AVAILABILITY STATEMENT}

All datasets generated for this study are included in the article/supplementary material.

\section{REFERENCES}

Chao, Y., Sheng, J. D., and Chun, F. L. (2016). Porous $\mathrm{TiNb}_{24} \mathrm{O}_{62}$ microspheres as high-performance anode materials for lithium-ion batteries of electric vehicles. Nanoscale 8, 18792-18799. doi: 10.1039/c6nr04992c

Gao, R. M., Lu, T. H., and Hu, J. (2016). Explicit expression of limit spectral density of gao wei sample covariance matrix. J. Jilin Univ. 54, 499-505. doi: 10.13413/j.cnki.jdxblxb.2016.03.17

Jia, S. C., and Yang, F. P. (2016). Study on fault data location of flexible Ac transmission controller. Comp. Simul. 33, 180-183.

Liu, J. B., Chen, C. X., and Xu, Y. Q. (2017). Deformation twinning behaviors of the low stacking fault energy high-entropy alloy: an in-situ TEM study. Script. Mater. 137, 9-12. doi: 10.1016/j.scriptamat.2017.05.001

Michael, C. G., Pan, G., and Jeffrey, A. H. (2017). Computational modeling of high-entropy alloys: structures, thermodynamics and elasticity. J. Mater. Res. 32, 3627-3641. doi: 10.1557/jmr.2017.366

Mike, B., Patrick, B., and Ronald, U. (2017). Multinucleated giant cells in the implant bed of bone substitutes are foreign body giant cells-new insights into the material-mediated healing process. J. Biomed. Mater. Res. A 105, 1105-1111. doi: 10.1002/jbm.a.36006

Rizzardi, Q., Sparks, G., and Maaß, R. (2018). Fast slip velocity in a high-entropy alloy. JOM 70, 1088-1093. doi: 10.1007/s11837-018-2856-6

Sheng, W., Wang, J. Q., and Wang, G., Huo, J., Wang, X., Li, R. W. (2018). Amorphous microwires of high entropy alloys with large magnetocaloric effect. Intermetallics 96:79-83. doi: 10.1016/j.intermet.2018.02.015

Shi, Q. R., Zhao, X. H., Shan, Z. B., and Shi, Y. W. (2016). FLOCC-ESPRIT based polarization array parameter estimation method. Autom. Instrum. 37, 2076-2083. doi: 10.3969/j.issn.0254-3087.2016.09.020

Stepanov, N. D., Yurchenko, N. Y., and Panina, E. S. (2017). Precipitationstrengthened refractory $\mathrm{A}_{10.5} \mathrm{CrNbTi}_{2} \mathrm{~V}_{0.5}$ high entropy alloy. Mater. Lett. 188, 162-164. doi: 10.1016/j.matlet.2016.11.030

Su, S., Li, P., Yan, Y. T., Yang, Y., Zhang, W. B. (2016). Comparison of control strategies in a battery/supercapacitor hybrid energy storage system. Chin. J. Power Sources 40, 585-587.

Wang Y. B., Yang, H. X., Geng, L., Guo, Y. K. (2016). Research on the surface quality stability of ultra thin germanium polished wafers. J. Chin. Acad. Electron. Inform. Technol. 11,527-531. doi: 10.1016/j.tsf.2017.07.001

Wu, W., Xie, S. J., Zhang, Z., Chen, W. M., and Pei, X. H. (2016). Control strategy analysis and design of supercapacitor energy storage system based on combined two-way Dc-Dc converter. J. Power Supply 14, 83-101.

\section{ETHICS STATEMENT}

The study was approved by Zhejiang Industry Polytechnic College and Zhejiang Runtu CO. LTD. All authors provided written informed consent.

\section{AUTHOR CONTRIBUTIONS}

The research studied the synthesis and application of the new high energy alloy material in energy conversion and storage. HZ studied the electrochemical properties of the new high entrance alloy material. JH did the experiments, and by comparing the new high entrance alloy materials with $\mathrm{FeSn}_{2}$, the new high entrance alloy materials have more advantages in capacity, electrochemical performance, capacity stability, and magnification during cyclic charging. HZ wrote the manuscript.

\section{FUNDING}

Public Technology Research Project of Shaoxing Science and Technology Bureau (No. 2013B70030).

Xu, Y. Q., Li, Y. H., Zhu, Z. W., and Zhang, W. (2018). Formation and Properties of $\mathrm{Fe}_{25} \mathrm{Co}_{25} \mathrm{Ni}_{25}$ (P, C, B, Si $)_{25}$ high-entropy bulk metallic glasses. J Non-Crystal Solids. 487, 60-64. doi: 10.1016/j.jnoncrysol.2018.02.021

Ye, Y. F., Liu, X. D., and Wang, S. (2016). The general effect of atomic size misfit on glass formation in conventional and high-entropy alloys. Intermetallics 78 , 30-41. doi: 10.1016/j.intermet.2016.08.005

Yi, P. L., Hui, J., and Sheng, G. (2017). A new strategy to design eutectic high-entropy alloys using mixing enthalpy. Intermetallics 91, 124-128. doi: 10.1016/j.intermet.2017.09.001

Yurchenko, N., Stepanov, N. D., and Shaysultanov, D. G. (2016). Effect of $\mathrm{Al}$ content on structure and mechanical properties of the alxcrnbtivzr $(\mathrm{X}=0 ; 0.25 ; 0.5 ; 1)$ high-entropy alloys. Mater. Charact. 121, 125-134. doi: 10.1016/j.matchar.2016.09.039

Zhang, L., Zhou, D., and Bang, S. L. (2018a). Anomalous microstructure and excellent mechanical properties of $\mathrm{Ni}_{35} \mathrm{Al}_{21.67} \mathrm{Cr}_{21.67} \mathrm{Fe}_{21.67}$ highentropy alloy with BCC and B2 structure. Mater. Lett. 216, 252-255. doi: 10.1016/j.matlet.2018.01.124

Zhang, W. K., Kong, Q. Y., and Weng, T. C. W. (2018b). Applications of femtosecond X-ray techniques in chemistry and energy materials science. Physics. 8:504-514. doi: 10.7693/wl20180803

Zhi, M. L., Fritz, K., and Blazej, G. (2017). Ab initio assisted design of quinary dual-phase high-entropy alloys with transformation-induced plasticity. Acta Mater. 136, 262-270. doi: 10.1016/j.actamat.2017. 07.023

Zhou, R., Liu, Y., Zhou, C. S. (2018). Microstructures and mechanical properties of C-containing fecocrni high-entropy alloy fabricated by selective laser melting. J. Intermetal. 94, 165-171. doi: 10.1016/j.intermet.2018. 01.002

Conflict of Interest: JH was employed by company Zhejiang Runtu CO. LTD.

The remaining author declares that the research was conducted in the absence of any commercial or financial relationships that could be construed as a potential conflict of interest

Copyright (c) 2020 Zhou and He. This is an open-access article distributed under the terms of the Creative Commons Attribution License (CC BY). The use, distribution or reproduction in other forums is permitted, provided the original author(s) and the copyright owner(s) are credited and that the original publication in this journal is cited, in accordance with accepted academic practice. No use, distribution or reproduction is permitted which does not comply with these terms. 